\title{
Longitudinal determination of resilience in humans to identify mechanisms of resilience to modern-life stressors: the longitudinal resilience assessment (LORA) study
}

\author{
A. Chmitorz ${ }^{1,2} \cdot$ R. J. Neumann ${ }^{3} \cdot$ B. Kollmann ${ }^{1,4}$ (I) K. F. Ahrens ${ }^{3} \cdot$ S. Öhlschläger ${ }^{3} \cdot$ N. Goldbach ${ }^{3} \cdot$ D. Weichert ${ }^{1}$.

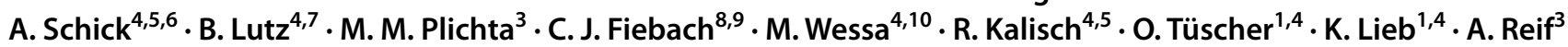

Received: 5 February 2020 / Accepted: 29 June 2020 / Published online: 18 July 2020

(c) The Author(s) 2020

\begin{abstract}
Resilience is the maintenance and/or quick recovery of mental health during and after periods of adversity. It is conceptualized to result from a dynamic process of successful adaptation to stressors. Up to now, a large number of resilience factors have been proposed, but the mechanisms underlying resilience are not yet understood. To shed light on the complex and time-varying processes of resilience that lead to a positive long-term outcome in the face of adversity, the Longitudinal Resilience Assessment (LORA) study has been established. In this study, 1191 healthy participants are followed up at 3- and 18-month intervals over a course of 4.5 years at two study centers in Germany. Baseline and 18-month visits entail multimodal phenotyping, including the assessment of mental health status, sociodemographic and lifestyle variables, resilience factors, life history, neuropsychological assessments (of proposed resilience mechanisms), and biomaterials (blood for genetic and epigenetic, stool for microbiome, and hair for cortisol analysis). At 3-monthly online assessments, subjects are monitored for subsequent exposure to stressors as well as mental health measures, which allows for a quantitative assessment of stressordependent changes in mental health as the main outcome. Descriptive analyses of mental health, number of stressors including major life events, daily hassles, perceived stress, and the ability to recover from stress are here presented for the baseline sample. The LORA study is unique in its design and will pave the way for a better understanding of resilience mechanisms in humans and for further development of interventions to successfully prevent stress-related disorder.
\end{abstract}

Keywords Longitudinal $\cdot$ Resilience $\cdot$ Modern-life stressors $\cdot$ Deep phenotyping

\section{Introduction}

Recent data from epidemiological surveys in the European Union show that each year, approximately $30 \%$ of the population suffer from a mental disorder, such as anxiety, depression, chronic pain, or addiction, that can at least to some

A. Chmitorz, R. J. Neumann, K. Lieb, A. Reif and B. Kollmann authors are contributed equally.

K. Lieb and A. Reif authors are contributed equally.

Electronic supplementary material The online version of this article (https://doi.org/10.1007/s00406-020-01159-2) contains supplementary material, which is available to authorized users.

B. Kollmann

bianca.kollmann@lir-mainz.de

Extended author information available on the last page of the article extent be traced back to the influence of exogenous or endogenous stressors (e.g., traumatizing events, challenging life circumstances or life transitions, or physical illness) [1]. The high incidence of stress-related disorders, the considerable individual burden, as well as socioeconomic costs associated with them make the promotion of mental health one of the great challenges industrialized countries currently have to face. Progress in our understanding of disease mechanisms and in the development of new therapies in the last decades has been limited despite intense research. The incidence of stress-related mental disorders remains high. It may be, therefore, essential to complement pathophysiological research with an alternative strategy, which is to investigate protective mechanisms that support the maintenance of mental health during and after adversity (e.g., potentially traumatizing events, challenging life circumstances, and physical illness). Focusing on resilience rather than on pathophysiology represents a paradigm shift in mental health 
research and has great potential for the development of new prevention strategies [2].

Psychological resilience refers to the observation that many individuals do not or only temporarily become ill, despite exposure to significant psychological or physical adversity [3-5]. In this regard, adversity refers to stressors of modern life including 'macrostressors' (i.e., potentially traumatizing events, such as man-made or natural disasters) as well as 'microstressors' or so-called 'daily hassles' (i.e., irritating, frustrating, and distressing demands that to some extent are part of every-day interactions with the environment) [6]. Focusing on mechanisms of resilience, rather than disease, may be a promising approach to promote the prevention of stress-related mental dysfunctions. Resilience has previously been considered to be a stable personality trait $[7,8]$. However, nowadays, most theorists define resilience as an outcome, i.e., the absence of mental or related somatic diseases after a potentially traumatizing event, or after a prolonged period of stress $[5,9,10]$.

One consequence of this conceptualization of resilience as an outcome is that resilience cannot be measured before an individual has encountered stressors, for example, by cross-sectionally using a personality questionnaire. We recently suggested a conceptual framework for the study of resilience and made proposals for outcome variables (compare [2]). In the simplest possible scenario, we suggested to relate the change in mental health problems $(\mathrm{P})$, measured at two time points $\left(\mathrm{T}_{\mathrm{A}}\right.$ and $\left.\mathrm{T}_{\mathrm{B}}\right)$, to the individual cumulative stressor load (i.e., the sum or amount of stressors) experienced between $\mathrm{T}_{\mathrm{A}}$ and $\mathrm{T}_{\mathrm{B}}$. In doing so, one can calculate a parametric score that expresses how an individual's mental health reacts to stressor exposure. It is assumed that a person is more resilient at $T_{B}$ if that person has developed less mental problems between $T_{A}$ and $T_{B}$ than expected in proportion to the accumulated stressor load. As a consequence, individuals with high cumulative stressor load and low mental health problems at a given time point are considered to be more resilient than, for instance, individuals experiencing an equal stressor load and more mental health problems in that same time period. Necessarily, to operationalize resilience as an outcome in this or comparable ways, prospective, longitudinal study designs are required $[9,11]$.

Current resilience research is still mainly phenomenological, often restricted to measuring the so-called 'resilience factors', that are statistically related to the outcome of resilience. Consequently, published reviews enumerate long lists of resilience factors, which include external factors, such as socioeconomic status or social support, internal factors, such as certain beliefs (e.g., self-efficacy) or skills (e.g., emotion regulation, problem solving), or more recently also neurobiological, (epi)genetic, hormonal, immunological, or other molecular factors [12-15]. Frequently, these factors explain only little variance in the outcome and are difficult to replicate [9]. Moreover, it has been noted that many of these resilience factors overlap conceptually and presumably mediate, correlate with, or depend on each other $[2,15]$. For instance, emotion regulation, coping, or problem solving are similar concepts and more distal factors such as social support, life history, or genotype may affect resilience by shaping the way an individual regulates his/her emotions or copes with stressors [2]. This calls for the identification and understanding of mediating mechanisms ('resilience mechanisms'), i.e., a presumably smaller number of shared cognitive, physiological and/or neural pathways, that provide protection against stress-related impairments.

To identify and investigate such resilience mechanisms, the Collaborative Research Center (CRC) 1193 'Neurobiology of resilience to stress-related mental dysfunction: from understanding mechanisms to promoting prevention', funded by the German Research Foundation (DFG), was established at the Universities of Mainz and Frankfurt and the Leibniz Institute for Resilience Research (LIR; formerly German Resilience Center) in Mainz. The CRC assesses resilience and its underlying mechanisms at several levels of analysis, integrating human studies and animal models in a translational manner. Central to the CRC 1193 is a large longitudinal human cohort study, the Longitudinal Resilience Assessment (LORA) study. This paper aims at providing an overview of the research program, the methods used, and to present baseline data of the LORA study cohort of enrolled healthy subjects.

\section{Research program}

LORA is currently conducted at the University Medical Center Mainz in cooperation with the LIR and the University Hospital of the Goethe University Frankfurt. It comprises a human cohort $N=1.191$ (Frankfurt: $n=611$; Mainz: $n=580$ ) that has been deep-phenotyped at study entry and is currently followed up for a minimum of 3 years in 18-month intervals. Between baseline assessments, participants are monitored every 3 months for mental health as well as encountered stressors in interim online stressor monitoring during the entire study period.

The two main research aims of the LORA study are:

- Aim 1 To characterize participants for their resilience to modern-life stressors over time and to operationalize resilience in a quantitative-parametric fashion (i.e., dimensionally rather than categorically).

- Aim 2 To identify and understand potential underlying mediating mechanisms of resilience to modern every-day life stressors. 
Furthermore, LORA has a third aim within the CRC 1193 consortium, namely to provide human subprojects within the CRC 1193 with deeply phenotyped subjects, systematically characterized for their longitudinal resilience outcome, for the purpose of experimentally investigating hypothesized resilience mechanisms in these subjects using, among others, neuroimaging and neurobiological methods.

\section{Tasks}

The main tasks to achieve the aforementioned aims are:

1. In-depth phenotyping of $N=1.200$ subjects at baseline assessments in 18-month intervals, including psychological, sociodemographic, environmental, lifestyle, genetic and epigenetic resilience factors, experienced stress in the months prior to the baseline measurement using hair cortisol samples, and microbiome analyses taken from stool samples in a community sample from the German RhineMain region. Also, a neuropsychological test battery is conducted at baseline and every 18 months, investigat- ing emotion regulation, cognitive flexibility, emotional interference inhibition, fear conditioning and extinction, and appraisal styles. Furthermore, repeated quantitative assessments of encountered modern-life stressors, including critical life events and daily hassles, as well as stressor-dependent changes in mental health (via interim online stressor monitoring) and biosamples (hair cortisol and microbiome), are assessed every 3 months to investigate resilience outcomes over time (see Fig. 1). Changes between the baseline assessments, together with information from the interim online assessments, will aid in operationalizing resilience in a dimensional fashion, including possible trajectories of resilience outcomes.

2. Using these data, potential underlying neuropsychological resilience mechanisms and/or biomarkers [such as (epi-) genetic markers and microbiome] shall be identified. Also, these assessments will aid in the identification and understanding of potential underlying mediating mechanisms of resilience to modern every-day life stressors.

3. Subprojects of the CRC 1193 that conduct experimental studies with humans will be provided with subjects that
B0/TO
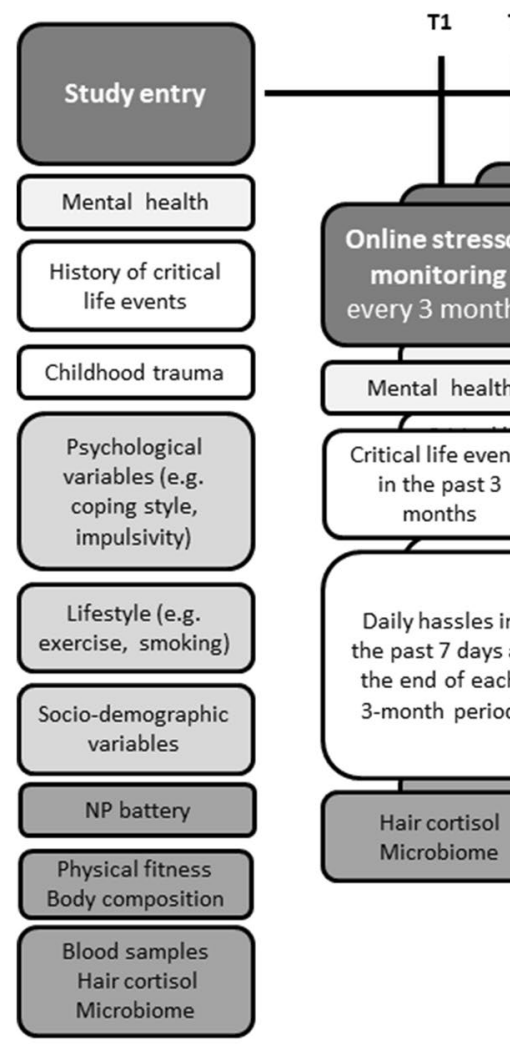

Online Stressor Monitoring

B1/T6

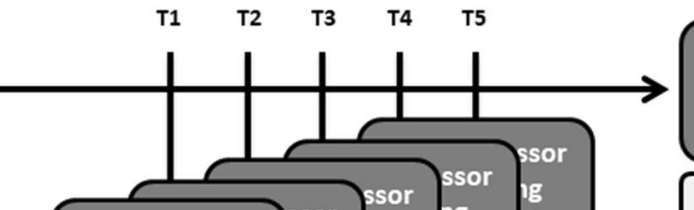

monitoring

every 3 months
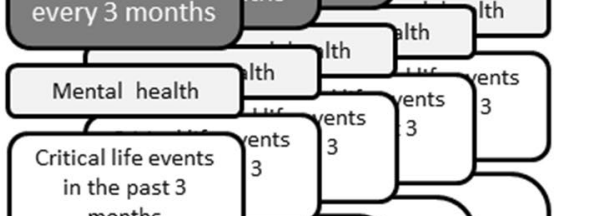

the past

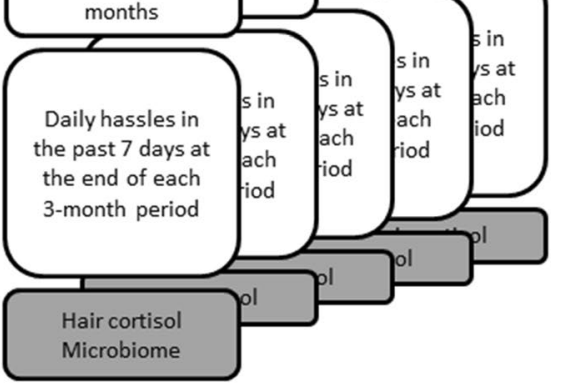

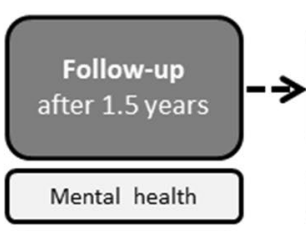

Psychological variables (e.g. coping style, impulsivity)

Lifestyle (e.g. exercise, smoking)

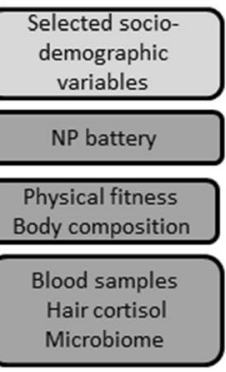

B2/T12

Follow-up after 1.5 years

Mental health

Psychological variables (e.g. coping style, impulsivity)

Lifestyle (e.g. exercise, smoking)

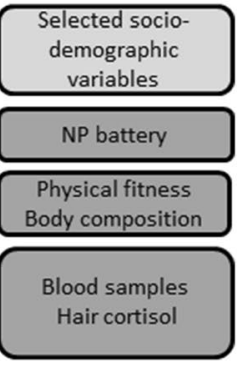

Note. NP battery: neuropsychological testing battery.

Fig. 1 LORA study design and assessment categories 
have been systematically characterized for their longitudinal resilience outcome. For this purpose, there are also cooperations with external projects. So far, these include: (1) EU H2020 funded project "Eat2BeNICE"; within the scope of this project, further analyses of the microbiome (via 16S rRNA sequencing) are funded. (2) By means of collaboration with the Psychiatric Genomic Consortium (PGC), we could secure funds for genomewide genotyping using the PsychChip. (3) A BEDREHELSE project on the epigenetic signature of ADHD allows to perform epigenome-wide analysis of part of the sample using the EPIC array; (4) EU H2020 funded project "DynaMORE" uses amongst others LORA data to develop an in silico model of stress resilience; (5) the State of Rhineland-Palatinate funded the Gutenberg Brain Study (GBS), which is a platform project of the LIR. The GBS has established a population-based sample of 4500 subjects from Mainz. Further collaborations are actively sought for, to leverage the information that is gathered in LORA and interested parties are asked to approach the LORA PIs to this end.

\section{Description of the LORA study design}

The LORA study is a population-based, prospective, longitudinal, multi-center cohort study including adults up to 50 years at study entry. Data collection for the first baseline assessment started on February 1st 2017 and continued until July 15th 2019. Planned longitudinal assessment will be ongoing for at least 3 years.

The study includes baseline assessments at the study centers: at study entry (B0/T0), at 1.5 years (B1/T6) and 3 years (B2/ T12), all participants are characterized in detail. Here, phenotyping includes questionnaires on sociodemographic, mental health, life history, psychological, and lifestyle-related variables (including upstream resilience factors) (see Table 1a). Furthermore, biological parameters (blood, stool, and hair samples), anthropometric and current physical fitness components, as well as a neuropsychological test battery are conducted. For the latter, battery tasks can be considered as proxy measures of the putative neurobiological resilience mechanisms (see Table 1b). Between baseline assessments, every 3 months, additional interim online stressor monitoring is conducted during the entire study period (see Fig. 1 for details on study design). The design allows for the assessment of healthy subjects of a large age range and follows them up as they are exposed to naturally occurring life stressors in a modern society.

\section{Sample recruitment}

Participants were recruited via online or printed advertisements, public advertisements (at the local universities, the university medical centers, libraries, shops, and gyms) and a webpage setup specifically for the project (https:// lora-studie.de/). Potential participants contacted the study centers via phone or e-mail.

Interested participants were then re-contacted by trained student assistants via phone or letter and provided with study information. They were screened for study eligibility by trained staff using structured in-house developed telephone interviews. Inclusion criteria were: age $18-50$ years (the upper age limit is set to minimize potential impacts of organic brain disorders), normal or corrected vision, sufficient mastery of the German language, and the ability to provide informed consent. Sufficient knowledge of German can be inferred from the telephone screening, which takes about $15 \mathrm{~min}$. Also, participants are asked during that screening, whether German is their mother tongue. However, being a non-native German speaker does not lead to study exclusion, as long as the language proficiency is sufficient to understand the content of the phone call. Exclusion criteria were: lifetime diagnosis of schizophrenia or bipolar disorder, organic mental disorders, substance dependence syndromes other than nicotine, as well as any other current severe axis I disorder or current severe medical conditions. Participants with known learning disabilities, serious neurological disorders (e.g., tumors in the central nervous system), or participants who had taken part in a drug trial in the previous 6 months were also excluded.

Participants who met the screening criteria were invited for an initial briefing session and gave written informed consent. Furthermore, participants were assessed diagnostically on the International Neuropsychiatric Interview (M.I.N.I [16, 17]) to rule out the existence of any current mental disorders. For $n=10$ participants, this screening was positive and further study participation was precluded (but referral to the outpatient departments of the respective participating study site's psychiatric department for further diagnosis and treatment was offered). Figure 2 provides an overview of the recruitment process. If the diagnostic interview was negative, participants were eligible for study participation and enrolled for full study assessment. Additionally, participants who completed less than $50 \%$ of the first baseline assessment (B0/T0) were excluded from further study participation. For the on-site baseline assessments, participants are monetarily reimbursed with $60 €$. Participation at the online stressor monitoring is rewarded with a token system, were subjects can gain up to three tokens per monitoring and 12 tokens per year. Each token is worth $5 €$ and is exchanged against a monetary compensation.

\section{Procedures}

According to the described study design, participants are invited on site to the baseline assessments for detailed characterization at 18-month intervals. In between baseline 
assessments, additional interim online stressor monitoring is applied every 3 months (see also Fig. 1). The detailed study design and applied assessment categories are described in detail below.

\section{Online database}

Besides on-site assessments at baseline and additional interim online stressor assessments, participants fill out questionnaires in an online data base system (secuTrial $\odot$ electronic data capture system, www.secutrial.com), which adheres to the Guidelines for Good Clinical Practice (GCP). The database provides an application for online assessments, through which the questionnaires assessing sociodemographic, lifestyle, and psychological variables are collected at the initial baseline assessment (B0/T0) and subsequent baseline assessments (B1/T6 and B2/T12), and the 3-month interim online stressor monitoring. All surveyed data are stored in the online data base system.

\section{Baseline assessments}

Participants who fulfil the inclusion criteria are invited to the baseline assessments for detailed characterization at the respective study centers. These are conducted on 2 days, which are separated by no more than 7 days.

B0/TO, day 1 (40-60 min) After an initial briefing session, written informed consent is obtained and participants are registered in the study database, where a random individual identification number is being generated.

Afterwards, the International Neuropsychiatric Interview (M.I.N.I.) [16] is used to rule out the existence of any current mental disorders. Provided that all inclusion criteria are met, the actual baseline assessment begins with the conduction of the multifaceted empathy test (MET) [38]. Blood samples are taken from the non-fasting participants by venous puncture ( $2 \times$ EDTA tubes; approximately $18 \mathrm{ml}$ ) to assess fluid biomarkers, including (epi-)genetic markers for genotyping. Blood samples are subsequently stored at refrigerator temperature until DNA isolation. Also, hair samples for cortisol determination are collected (see supplement for detailed information about biosample outcomes). For hair samples, two to three hair strains of at least 3-cm length are cut as close as possible to the scalp at the posterior vertex region [74]. Samples are wrapped in aluminium foil; the scalp end was marked and stored in a dark, dry place at room temperature until the end of complete baseline assessment. Given an average hair growth rate of $1 \mathrm{~cm}$ per month, earlier described by Wenning [75], the examination of 3-cm hair segment allows to assess cumulative hair cortisol concentration over a period of 3 months, consistent with assessed stressor load every 3 months. Hair samples are collected of all participants, who agree to submit a sample. Information about (chemical) hair treatments (i.e., colouring, perms, or using a strengthening iron) prior to sample collection is gathered. For participants with hair shorter than $3 \mathrm{~cm}$, no hair samples are collected, but these participants will remain in the study. Since participants are asked to send in their hair samples by mail for the following five interim online stressor monitoring, they are also provided with packing material for the following five measurement time points (T1-T5; 3, 6, 9, 12 , and 15 months). Anthropometric measurements (weight, height, hip, and waist circumferences) are conducted using a calibrated electronic scale (Seca, Birmingham, UK) with an accuracy of $0.1 \mathrm{~kg}$ for weight and a stadiometer (Seca) with an accuracy of $0.1 \mathrm{~cm}$ for height (participants were not wearing shoes). Waist circumference is measured to the nearest $0.1 \mathrm{~cm}$ midway between the lowest rib and the top of the iliac crest. Hip circumference measurement is taken around the widest portion of the buttocks. Both measures are conducted according to the WHO recommendations [76]. For the stool sample collection, the OMNIgene•Gut kits (DNA Genotek Inc. Ttawa, ON, Canada) are used. These consist of a tube of stabilisation liquid and a ball bearing. Two tubes, as well as a user manual for the stool sample collection at B0/T0 and the first 3-month measurement time point (T1), are handed out to the participants. They are asked to place stool faeces in the tube lid, which is designed to break up the faeces, and return the first tube at day 2, within 7 days. The second tube from $\mathrm{T} 1$ is returned by mail 3 months later. On arrival the samples are frozen immediately at $-80^{\circ} \mathrm{C}$.

Finally, participants are introduced to the online assessment application of the database for questionnaire assessments and asked to complete the questionnaires within a week. Questionnaires entail items assessing socio-demographics, mental health, life history, psychological, and lifestyle-related variables. The estimated completion time is $160 \mathrm{~min}$. A complete list of applied questionnaires is given in Table 1a.

B0/TO, day 2 (approx. $180 \mathrm{~min}$ ) First, participants hand in stool samples and take part in a drug screening. If the screening is negative, they are then asked to proceed. If screened positive, participants are excluded from the study. Then, participants are asked to fill out questionnaires measuring state-dependent variations in anxiety (i.e., State-Trait Anxiety Inventory; STAI-S [77, 78]) and the Positive and Negative Affect Schedule (PANAS; [50]). This is followed by a neuropsychological test battery, which assess the following potential neuropsychological resilience mechanisms: (a) cognitive flexibility, (b) emotional interference inhibition, (c) positivity bias, (d) volitional emotional regulation, and e) differential fear conditioning (discrimination) and extinction. Table $1 \mathrm{~b}$ provides a description of the tasks and the measured potential underlying neuropsychological mechanisms. Subsequently, subjects are asked to participate 
Table 1 (a) Questionnaires and (b) neuropsychological tests used in the LORA study

(a) Questionnaires

\begin{tabular}{|c|c|c|c|c|c|}
\hline Topic & Questionnaire & $B$ & $F$ & $3 \mathrm{~m}$ & $\# I$ \\
\hline \multirow[t]{3}{*}{ Mental health } & General health questionnaire-28 (GHQ-28) $[18,19]$ & $\mathrm{x}$ & $\mathrm{x}$ & $\mathrm{x}$ & 28 \\
\hline & Health questionnaire for patients (PHQ-D) $[20,21]$ & $\mathrm{x}$ & $\mathrm{x}$ & & 16 \\
\hline & Mini international neuropsychiatric interview (M.I.N.I.) $[16,17]$ & $\mathrm{x}$ & $\mathrm{x}$ & & \\
\hline \multicolumn{6}{|l|}{ Micro- and macrostressors } \\
\hline History of critical life events & Life events checklist from LHC (adapted from Canli et al. [22]) & $\mathrm{x}$ & $\mathrm{x}$ & $\mathrm{x}$ & 27 \\
\hline Daily hassles & Mainz Inventory of Microstressors (MIMS) [23, 24] & $\mathrm{x}$ & $\mathrm{x}$ & $\mathrm{x}$ & 58 \\
\hline Childhood Trauma & Childhood trauma questionnaire (CTQ) $[26,27]$ & $\mathrm{x}$ & $\mathrm{x}$ & & 25 \\
\hline Perceived stress & $\begin{array}{l}\text { Perceived stress scale (PSS) [28]; unpublished translation by A. Büss- } \\
\text { ing, University of Witten/Herdecke }\end{array}$ & $\mathrm{x}$ & $\mathrm{x}$ & $\mathrm{x}$ & 10 \\
\hline Maltreatment and abuse & Maltreatment and abuse chronology of exposure (MACE) [29] & & $\mathrm{x}$ & & 18 \\
\hline Trauma & Harvard trauma questionnaire (HTQ) [30] & & $\mathrm{x}$ & & 35 \\
\hline \multicolumn{6}{|l|}{ Psychological variables } \\
\hline Ability to bounce back & Brief resilience scale (BRS) $[31,32]$ & $\mathrm{x}$ & $\mathrm{x}$ & & 6 \\
\hline Cognitive emotion regulation & Cognitive emotion regulation questionnaire (CERQ) $[33,34]$ & $\mathrm{x}$ & $\mathrm{x}$ & & 29 \\
\hline Coping flexibility & Coflex [35]; German version translated by study site & $\mathrm{x}$ & $\mathrm{x}$ & & 13 \\
\hline Coping style & Brief Cope $[36,37]$ & $\mathrm{x}$ & $\mathrm{x}$ & & 28 \\
\hline Empathy & Multifaceted empathy test (MET) (subsection: accuracy) [38] & $\mathrm{x}$ & $\mathrm{x}$ & & 40 \\
\hline Hardiness & Hardiness Scale ([39]; translated by study site) & $\mathrm{x}$ & $\mathrm{x}$ & & 12 \\
\hline Impulsive behavior & $\begin{array}{l}\text { Urgency Premeditation Perseverance and Sensation Seeking Impulsive } \\
\text { Behavior Scale (UPPS) }[40,41]\end{array}$ & $\mathrm{x}$ & $\mathrm{x}$ & & 45 \\
\hline Impulsivity & Eight item impulsive behavior scale (I-8) [42] & $\mathrm{x}$ & $\mathrm{x}$ & & 8 \\
\hline Interpersonal reactivity & Interpersonal reactivity index (IRI) [43] & $\mathrm{x}$ & $\mathrm{x}$ & & 28 \\
\hline Locus of control & Locus of control scale $[44,45]$ & $\mathrm{x}$ & $\mathrm{x}$ & & 28 \\
\hline Optimism & Life orientation test (LOT-R) $[46,47]$ & $\mathrm{x}$ & $\mathrm{x}$ & & 10 \\
\hline Perceived social support & Social support questionnaire (F-SozU) [48] & $\mathrm{x}$ & $\mathrm{x}$ & & 14 \\
\hline Personality & Big-five-inventory (BFI-10) [49] & $\mathrm{x}$ & $\mathrm{x}$ & & 10 \\
\hline Positive and negative affect & Positive and negative affect schedule (PANAS) $[50,51]$ & $\mathrm{x}$ & $\mathrm{x}$ & & 20 \\
\hline Positive appraisal style & gPASS (Kalisch et al. in prep.) & $\mathrm{x}$ & $\mathrm{x}$ & & 29 \\
\hline Resilience factors & Connor-Davidson resilience scale (CD-Risk) $[52,53]$ & $\mathrm{x}$ & $\mathrm{x}$ & & 25 \\
\hline Self-efficacy & General self-efficacy scale (GSE) [54] & $\mathrm{x}$ & $\mathrm{x}$ & & 10 \\
\hline Sense of coherence & Orientation to life questionnaire $[55,56]$ & $\mathrm{x}$ & $\mathrm{x}$ & & 29 \\
\hline Social desirability & Social desirability scale-gamma (KSE-G) [57] & $\mathrm{x}$ & $\mathrm{x}$ & & 6 \\
\hline State-Trait Anger & State-trait anger anxiety questionnaire (STAXI) [58] & $\mathrm{x}$ & $\mathrm{x}$ & & 44 \\
\hline Well-being & WHO questionnaire on well-being (WHO 5) $[59,60]$ & $\mathrm{x}$ & $\mathrm{x}$ & & 5 \\
\hline Identity & $\begin{array}{l}\text { Adapted from Skalen zur Messung der ethnischen Identität (MEIM) } \\
\text { (GESIS [61]) }\end{array}$ & & $\mathrm{x}$ & & 7 \\
\hline Humiliation & Humiliation scale (Lindert and Mollica, in prep.) & & & & 26 \\
\hline \multicolumn{6}{|l|}{ Sociodemographic variables } \\
\hline General sociodemographic data & $\begin{array}{l}\text { General questionnaire for sociodemographic data, family history, } \\
\text { ethnical background, employment/salary }\end{array}$ & $\mathrm{x}$ & $\mathrm{x}$ & & 56 \\
\hline Migration & Migration status questionnaire (based on Nesterko and Glaesmer) [62]) & $\mathrm{x}$ & $\mathrm{x}$ & & 5 \\
\hline \multicolumn{6}{|l|}{ Lifestyle variables } \\
\hline Alcohol use disorder & Alcohol use disorder identification test (AUDIT) [63] & $\mathrm{x}$ & $\mathrm{x}$ & & 10 \\
\hline Nicotine dependence & Fagerstrom test for nicotine dependence [64] & $\mathrm{x}$ & $\mathrm{x}$ & & 6 \\
\hline Drug consumption & $\begin{array}{l}\text { General questionnaire about illegal drug consumption (questionnaire } \\
\text { created by study sites) }\end{array}$ & $\mathrm{x}$ & $\mathrm{x}$ & & 6 \\
\hline Physical activity & International physical activity questionnaire (IPAQ) $[65,66]$ & $\mathrm{x}$ & $\mathrm{x}$ & & 27 \\
\hline Physical fitness & International fitness scale (IFIS) [67] & $\mathrm{x}$ & $\mathrm{x}$ & & 5 \\
\hline General health variables & $\begin{array}{l}\text { General questions concerning health and lifestyle (based on: GESIS } \\
\text { [61]) }\end{array}$ & & & & 12 \\
\hline
\end{tabular}


Table 1 (continued)

Neuropsychological tests

Resilience mechanism

Task description

Psychological flexibility

For the assessment of switch costs, stability (distractor inhibition cost), and dispositional flexibility (i.e., the spontaneous switching rate in the face of ambiguous cues); the stability/ flexibility task is used. Participants continuously perform a task on digits presented above a fixation cross (ongoing task, e.g., odd/even judgment on digits between 1 and 9). Infrequently, a second digit is presented beneath fixation, and depending on three different brightness conditions, participants have to either switch to the lower digit and perform a different task when the lower digit is brighter (e.g., $</>5$ judgment; flexibility condition) or ignore the lower digit when it is darker than the upper digit (distractor inhibition; stability condition). In the third of three conditions, the brightness difference between the two digits is so subtle that it is not consciously detectable (ambiguous condition). Here, the spontaneous switching rate is examined as an indicator of dispositional cognitive flexibility; established by Armbruster et al. [68]

Emotional interference inhibition

Positivity bias

A classical flanker task, assessing emotional response interference inhibition, during which participants need to respond to a target cue presented in the center of the screen, surrounded by distractor cues. Before each target cue presentation, participants see a picture from the International Affective Picture Set (IAPS) database for $500 \mathrm{~ms}$, differing in emotional valence (i.e., aversive or neutral). Then, a row of seven arrows is presented, which either all point congruently to the left/ right side or the target cue points to the opposite site compared to the other arrows (i.e., incongruent trial). Participants are instructed to indicate the pointing direction of the target cue as fast and accurately as possible via a button press on the keyboard with the respective index finger (right index finger for right-pointing target cue; left index finger for left-pointing target cue). Participants receive direct written feedback on the screen for an incorrect or too slow (>1000 ms) response. After each of five task runs, participants receive feedback about the percentage of correct responses within that run and their average reaction time displayed on the screen. Important outcomes are the reaction time and accuracy differences between congruent and incongruent task trials, between aversive and neutral trial pictures, as well as the interaction of both (congruency x valence); adapted from Stahl et al. [69]

Information processing biases favoring positive versus negative information in attention and interpretation will be assessed with a visual probe task (VPT; [70]) and an ambiguous cue task (ACT; a variant of the task paradigm described in Schick et al. 2013 [71], with visual instead of auditory stimulus material), respectively. In the VPT, participants respond to abstract probe stimuli following the presentation of emotional faces (happy, fearful, and neutral). Positivity biases in attention are inferred from accelerated responses to probes that replace happy as opposed to neutral or negative faces. In the ACT, participants learn to associate two visual cues (e.g., a long and a short bar) with positive vs. negative monetary consequences. In the test phase, participants are presented with ambiguous cues (bars of medium length). Responses indicate an individual tendency to interpret ambiguous information as positive or negative 
Table 1 (continued)

Neuropsychological tests

Resilience mechanism

Task description

Volitional emotion regulation

Participants are presented with pictures of differing emotional valence (i.e., aversive and neutral) from the International Affective Picture Set (IAPS). For each picture, participants receive one of three instructions on screen: regard the picture, reappraise (i.e., situation-focused reappraisal), or dissociate. In the regarding condition, participants are expected to carefully look at the picture, take in all its details. In the reappraise condition, participants are asked to change their appraisal of the presented picture scene to regulate their emotions, e.g., by telling themselves that the presented picture is just a scene performed by actors. The dissociation condition is another way of regulating emotions, in which participants are asked to distance themselves actively from the picture content, e.g., by making themselves aware that they do not know the displayed people in the picture. After each picture presentation, participants are asked to rate the intensity of their feeling at that moment as fast as possible on a visual analogue scale from very week to very strong. Participants undergo a short instruction phase with example pictures to get familiar with the different emotion regulation strategies. Main outcomes are differences in the emotion ratings and reaction times and electromyographic (EMG) activity between task conditions; established by Schönfelder et al. [72, 73]. Before the experiment starts, three electrodes are placed on the forehead of the subject for EMG recordings. Two electrodes are placed above the left eyebrow for corrugator muscular activity assessment, while the ground electrode is placed close to the hairline, above all facial muscles (gel-filled electrodes, Biopac ${ }^{\circledR}$ Systems, Inc.)

Differential fear conditioning (discrimination) and Classical fear conditioning task, using two different geometric figures as CS + and CS -, respectively, which are counterbalanced either a square or a diamond shape. The $\mathrm{CS}+$ is paired with an aversive UCS [i.e., electrodermal stimulation; Digitimer DS7A(CE)] in 50\% of all presentations during the acquisition phase by a pain electrode attached to the back of the right hand. Before the acquisition phase, participant's individual pain threshold is calibrated to reach a pain level that is higher than six on a scale from 0 ("I do not feel anything") to 10 ("The strongest pain I can imagine being applied with such an electrode"). After each CS + or CSpresentation, participants are asked to rate their level of anxiety, fear or tension as fast as possible on a visual analogue scale from "not at all" to "very much". During extinction, the $\mathrm{CS}+$ is never coupled with the US. After the experiment, participants are asked, which symbol was coupled with the pain stimulation, to make sure that they learned the CS + UCS pairing. During the experiment, participant's skin conductance rate (SCR) is measured with two electrodes attached to the palm of the left hand (Biopac ${ }^{\circledR}$ Systems, Inc.)

Notes: $B$ baseline, $F$ follow-up at main assessments every 18 months; $3 \mathrm{~m}=$ interim analyses every 3 months; $\# I=$ number of total items

in a detailed assessment of bodily composition and several physical fitness components. This part is optional for the participants (see supplements for details).

B1/T6 and B2/T12, day 1 (approx. 40 min: The procedure for these measurement time points substantially matches the one described for day 1 of $\mathrm{B} 0$. The International
Neuropsychiatric Interview (M.I.N.I.) [16] is conducted again, to test for potential current mental disorders. If screened positively, subjects are not excluded from the study; however, trained staff decides in joint consultation with the participant, whether the participant is stable enough to complete the whole assessment. Nevertheless, referral to 
the outpatient departments of the psychiatric departments for further diagnosis and treatment will be offered for positively screened subjects. Participants are kept in the study to follow-up on the possible recovery from these mental illnesses and to investigate the skills, traits, and/or external factors (e.g., psychotherapy and hospital treatment) that might have helped them recover. Regarding biosamples, only one blood tube for epigenetic markers is taken and participants are provided with one tube for the stool sample at B1/T6 and packing material for hair samples for the following five measurement time points ( $3,6,9,12$, and 15 months).

B1/T6 and B2/T12, day 2 (180 $\mathrm{min})$ The same procedure as described for day 2 of the baseline (B0/T0) is repeated.

Of note, in Frankfurt, the two described assessment days are conducted in 1 day, due to organizational reasons. Still, the questionnaires have to be filled out within 7 days. Furthermore, participants are provided with shipping material for the first stool sample at baseline.

\section{Interim online stressor monitoring (T1-T5, T7-T11)}

In between the main assessments on-site, participants are asked to report their individual mental health status (GHQ28) online, as well as individual exposures to life stressors every 3 months. Here, macro stressors, such as critical or major life events (CLE) and incidents of potentially traumatizing events (PTE), as well as microstressors, more precisely daily hassles (DH) are assessed, as described in detail in the procedure section and supplementary material. Additionally, participants send back hair samples (T1-T5, T7-T11) as well as gut samples (T1) via mail.

\section{Data management}

Data collected via the online assessment application (SecuTrial database) (see above) are double-checked for consistency and plausibility. In case of missing, inconsistent or implausible data, participants are contacted by the study assistants. Furthermore, the SecuTrial database fulfils all requirements regarding data storage and protection according to national laws. Subproject-specific data (i.e., neuropsychological and physiological data) will be entered into sub-databases of the central Z03 database, designated to the specific subproject. Access to these sub-databases can only be granted by the leading principal investigators and very few assigned staff members and are only made available for the principal investigators of the specific subproject.

\section{Planned statistical analyses}

The longitudinal procedures allow us to link individual properties, collected during baseline assessments on behavioral, biological, and neuropsychological levels, to stress reactivity in a longitudinal matter. By this, resilience processes can be identified. Resilience will be indexed by the reactivity of individuals' mental health to stressors during 3-month time intervals in a 'stressor reactivity' (SR) score, derived using a residualization approach, previously introduced by Kalisch et al. [11], which investigates the relationship between stressors, operationalized by a combined score of daily hassles and life events over time, against general health, investigated using the GHQ score over time. The SR scores can then be calculated using a sliding window approach of overlapping time windows to reduce data loss, which reflects intra-individual temporal variability in resilience. We will
Fig. 2 Flow chart of sample recruitment

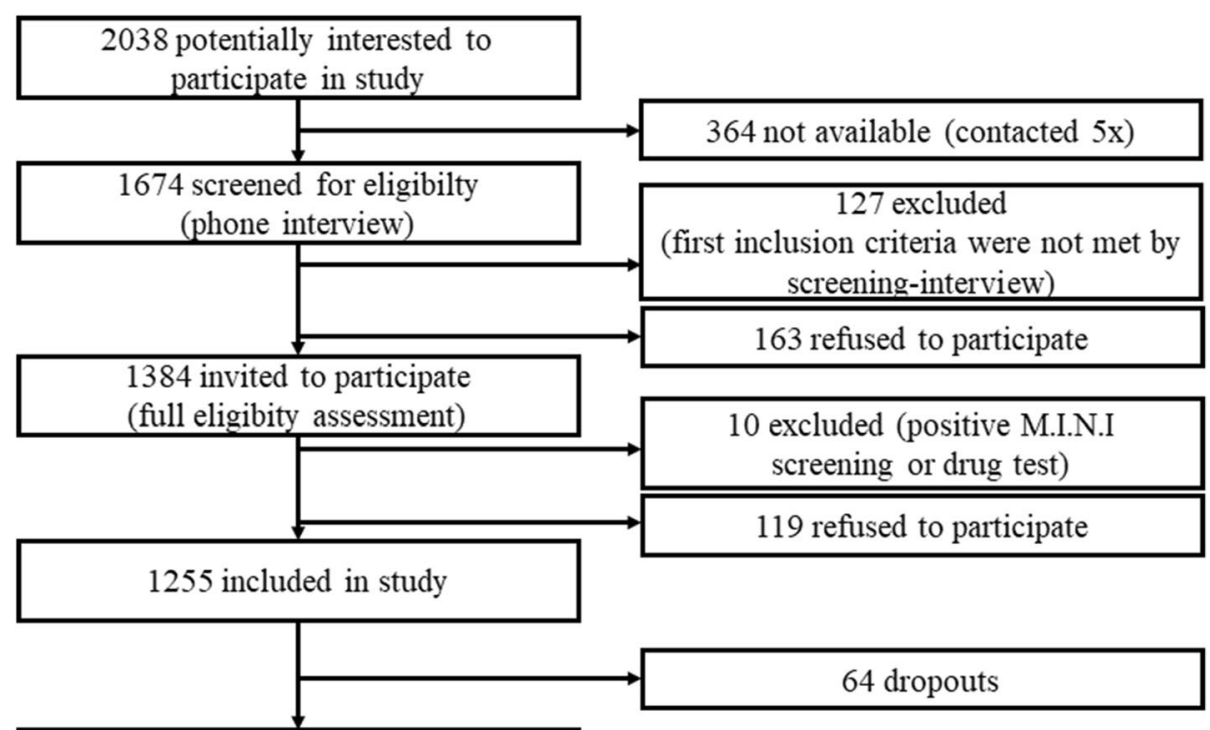

$1191 \mathrm{~T} 1$ assessment with more than $50 \%$ of the data 
investigate homeostatic adaptation, testing whether a potential resilience mechanism can satisfactorily predict SR over a longer period of time. Furthermore, we will investigate possible allostatic adaptations, which are hypothesized to take place when resilience mechanisms need to change or be adapted for a system to stay resilient, because the stressor exposure temporarily exceeds the system's capacity. For the examination of allostatic adaption, changes in neuropsychological performance over time are assumed to be crucial. For more detailed information, we refer to Kalisch et al. [9, 11].

\section{Baseline data of recruited participants}

For the resilience assessment, in total, a sample of 1255 healthy subjects from the Rheine-Main region spanning from Mainz $(n=624)$ to Frankfurt $(n=631)$ were enrolled, of which 1191 subjects completed at least $50 \%$ of the first baseline assessment (B0/T1) (see Fig. 2). Blood for DNA isolation has been acquired from $n=1,009$ participants, stool samples for microbiome analyses from $n=1,041$
Table 2 Baseline data of the LORA study sample $(N=1191)$

\begin{tabular}{|c|c|c|c|}
\hline Variable & $n$ & Percentage & Range \\
\hline \multicolumn{4}{|l|}{ Gender } \\
\hline Female & 783 & 65.9 & \\
\hline Male & 406 & 34.1 & \\
\hline Age $(M / S D)$ total & 1188 & $28.59(7.96)$ & $18-50$ \\
\hline$<20$ years & 63 & 5.30 & \\
\hline 20-29 years & 724 & 60.94 & \\
\hline $30-39$ years & 246 & 20.71 & \\
\hline$>40$ years & 155 & 13.05 & \\
\hline \multicolumn{4}{|l|}{ Nationality } \\
\hline German & 1083 & 91.86 & \\
\hline Other European countries & 51 & 4.32 & \\
\hline Others $(\%)$ & 45 & 3.82 & \\
\hline \multicolumn{4}{|l|}{ Marital status } \\
\hline Non-married & 867 & 80.50 & \\
\hline Married & 182 & 16.90 & \\
\hline Separated & 9 & 0.84 & \\
\hline Divorced & 16 & 1.49 & \\
\hline Widowed & 3 & 0.28 & \\
\hline \multicolumn{4}{|l|}{ Highest educational achievement } \\
\hline No school-leaving qualification & 1 & 0.09 & \\
\hline School-leaving certificate & 2 & 0.19 & \\
\hline Certificate of Secondary Education & 29 & 2.69 & \\
\hline School-leaving examination & 420 & 38.92 & \\
\hline Completed vocational training & 147 & 13.62 & \\
\hline University degree & 480 & 44.49 & \\
\hline \multicolumn{4}{|l|}{ Employment } \\
\hline Full time & 342 & 31.78 & \\
\hline Part time & 131 & 12.17 & \\
\hline Part time due to health issues & 3 & 0.28 & \\
\hline No employment due to reasons other than health issues & 24 & 2.22 & \\
\hline No employment due to health issues & 2 & 0.19 & \\
\hline Currently obtaining an education & 574 & 53.35 & \\
\hline Number of previous life events (lifetime), $M(\mathrm{SD})$ & 1188 & $11.81(7.14)$ & $0-39$ \\
\hline Number of daily hassles (past 7 days), $M(\mathrm{SD})$ & 1149 & $63.66(27.14)$ & $0-175$ \\
\hline GHQ, overall, $M(\mathrm{SD})$ & 1183 & $16.55(7.62)$ & $0-49$ \\
\hline BRS score, $M(\mathrm{SD})$ & 1182 & $3.76(0.67)$ & $1-5$ \\
\hline PSS score, $M(\mathrm{SD})$ & 1186 & $12.46(5.74)$ & $0-31$ \\
\hline
\end{tabular}

Notes: Percentage based on valid data; mean and standard deviation based on all obtained data, extreme outliers excluded 
participants, and hair for cortisol determination from $n=927$ participants at baseline.

In the following, we describe the baseline data regarding outcome-based resilience measures and the assessment of perceived stress and stressors. Descriptive demographic statistics of the sample is shown in Table 2. Participants' age ranged from 18 to 50 years and the sample is biased towards females $(66 \%)$. Although $8 \%$ of the sample participants are of non-German nationality, all of them have sufficient knowledge of the German language, as is inferred from the screening interview and the interactions during the assessment. A considerably high number of participants are non-married $(80 \%)$, most likely due to their rather young age. The overall education level can be considered as being rather high, since nearly half of the sample (44.5\%) holds a university degree. More than half (53.4\%) of the B0/T0 sample participants are still obtaining a degree at the time of the B0/T0 measurement.

Based on all data from the baseline assessment (see Supplement for detailed description of the scoring), excluding extreme outliers $( \pm 4$ or more standard deviations of the mean), participants reported a mean of 11 major life events during lifetime (Fig. 3a). Furthermore, the number of experienced life events correlated positively with participant's age $(r=0.36, p<0.001)$. The median number of chronic and daily hassles was 60 , with a mean $=63.66$ (Fig. 3b). On average, reported daily hassles equal almost ten hassles per day. In the self-assessment test of perceived stress (PSS-10), most participants indicated a stress level of $12($ median $=12)$, which can be considered as rather low; $33.6 \%$ report to be moderately-to-highly stressed.

Reported psychological symptoms at baseline, assessed by the GHQ-28, were non-normally distributed, with positive skewedness of $1.49(\mathrm{SE}=0.07)$ and kurtosis of 1.45 $(\mathrm{SE}=0.14)$. As shown in Fig. 3c, 993 participants reported symptoms below the threshold of $23 / 24$ points [19]. Of note, the 190 (14\%) subjects scoring above the diagnostic threshold did not fulfil the criteria of a mental disorder according to the initial M.I.N.I. assessment. (a) Number of previous life events (lifetime), 4 extreme outliers excluded

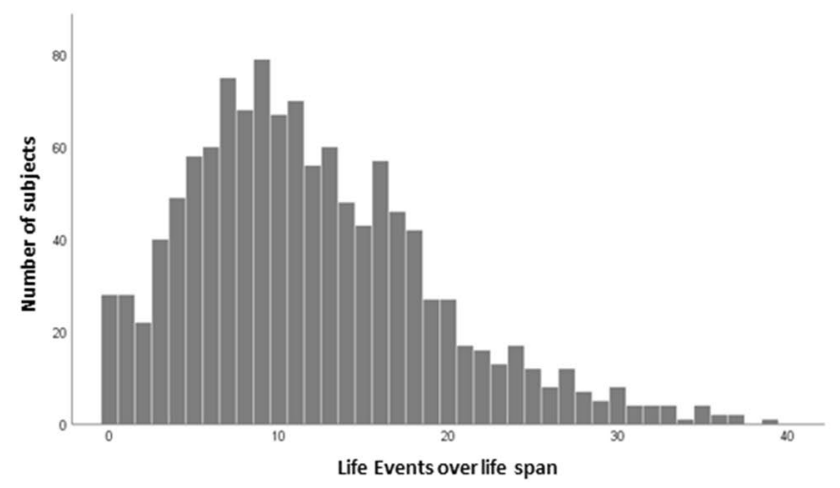

(c) GHQ-28 scores at baseline assessment, 1 extreme outlier excluded

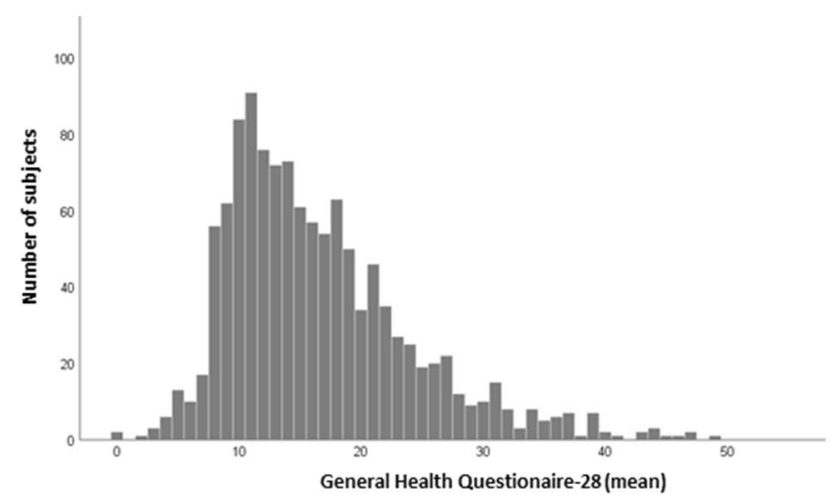

(b) Number of chronic and daily hassles (previous week), 6 extreme outliers excluded

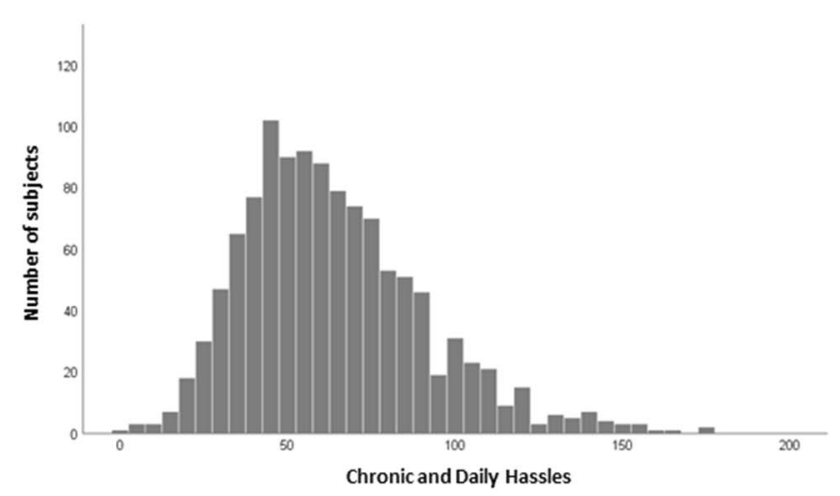

Fig. 3 Frequency of previous life events, chronic and daily hassles, and mental health 


\section{Current and future work}

As of July 2019, the first baseline assessment (B0/T0) has been completed for all participants at both sites. Interim online stressor monitoring, as well as the second baseline measurement (B1/T6) are ongoing. The third baseline measurement (B2/T12), which is 3 years post-study onset, will be assessed in the first subjects in Mainz and Frankfurt in February 2020. The unique study design and analysis scheme, as outlined in Fig. 1 will be continued. We plan to follow up the 1191 participants enrolled at B0/T0 (baseline) for another 3 years (up to early B4/T24).

\section{Discussion, limitations, and outlook}

We have postulated that resilience is not simply the absence of mental health problems, but rather a process that can be operationalized as the amount of stress and daily hassles a person encounters over time in relationship to the general health outcome that person shows [2].This calls for the use of longitudinal approaches to investigate resilience mechanisms in more depth. The LORA study uses a unique design to assess resilience over a time period of at least 3 years, being able to observe resilience mechanisms, while they occur in response to modern-life stressors. This is done by extensively capturing participant's stressor load with intermediate online stressor monitoring every three months, representing a very high sampling rate. This monitoring not only assesses the influence of life events, but also captures modern every-day life stressors, the so-called daily hassles, assessed with the Mainz Inventory of Microstressors (MIMIS; [25]), giving a good overview of minor and major stressors, together with their temporal extend. The stressor monitoring includes also hair cortisol samples, resulting in a more objective way to capture undergone stress and activation of the hypothalamic-pituitary-adrenal (HPA) axis over the last 3 months [79].

Moreover, several cognitive abilities, which are assumed to be affected under stress, are tested with a neuropsychological test battery during the baseline assessment time points every 18 months. The repeated application of this neuropsychological test battery in the LORA study will give new insights into the duration of these influences, possible interindividual differences, and are a proxy for the underlying neurobiological processes taking place in resilience. Most importantly, this neuropsychological battery may shed light on the resilience mechanisms taking place in between assessment time points.

Resilience mechanisms might also include alterations of gene expression, e.g., via epigenetic modifications such as DNA methylation. Thereby the environment may interact with gene regulatory networks, such as the glucocorticoid system. Studies in rats and postmortem studies in humans have, e.g., shown that an increase in the glucocorticoid receptor (encoded by $\mathrm{NR3Cl}$ ) promoter methylation later leads to higher stress resilience, pointing to an allostatic adaption of the stress axis as a consequence of life events [80]. These and other studies provide first clues on how the genetic makeup might interact with the environment to affect resilience outcomes. Furthermore, there might be genetic variants that could more directly influence adaptation processes to stressors [81]. To this end, DNA is sampled in LORA to generate genome-wide SNP analyses and epigenome-wide analyses to further examine their link with resilience mechanisms.

In the LORA study, also data concerning physical fitness levels and body composition are collected, since there is plenty of evidence that physical fitness, achieved through regular physical exercise, yields physical and mental health benefits by influencing stress responses [82, 83]. Furthermore, Mujica-Parodi and colleagues [84] showed that increased body fat was related to elevated cortisol reactivity and decreased cognitive performance, particularly spatial processing, selective attention, and working memory. As such, body fat percentage can also have an impact on stress responsivity and cognitive performance, rendering it a worthwhile resilience mechanism to investigate.

As is known from recent studies, the gut-brain axis also plays an important role in stress responses. For example, stress was shown to reduce the bacterial levels in the gut flora of a student sample during exam weeks, indicating an influence of stressor exposure on the gastrointestinal microflora [85]. Hence, the stool samples collected in the present study can give important information on the influences of stress on a person's microbiome and how a certain microbiota composition determines stress responses in the individual.

A total of 1255 participants have been recruited in the LORA study, which exceeds the originally planned 1200 participants. Of those enrolled participants, 1191 participants have completed more than $50 \%$ of the assessment at baseline. Slightly more women are enrolled in the study (65.9\%) and most participants are rather highly educated, with $44.9 \%$ having a university degree and more than half of the sample currently obtaining one. However, highly educated samples are a phenomenon commonly observed in large-scale studies, such as the present one [86]. University students are a quite homogenous group of people. They are easy to recruit and potentially have a higher economic motivation to participate in studies and also have sufficient time to take part in longitudinal studies, like the present one. However, they might not be representative for the world population [87]. Therefore, the results should be interpreted with caution. It is unclear whether students are a group of people who are usually exposed to relatively small amounts of stress, or even to a lot of stress and if they have 
better coping mechanisms compared to the world population. However, the rather low amount of perceived stress on the PSS-10 in the present study infers a rather reduced level of stress exposure in the current sample compared to other studies (e.g., [88]). Participants show a medium amount of previous life events, with a mean $=11.81$, and a rather low number of daily hassles with on average almost 64 hassles (mean $=63.66$ ). Participants' general health was good, as indicated by a GHQ mean score of 16.55 , with none of the participants showing any psychiatric disorders on axis I, as assessed on the M.I.N.I. interview [16]. The mean BRS score was within the range of previously reported BRS means in comparable German populations $(M=3.58$ and $M=3.37$; [31] and $M=3.35$; [90]). Hence, the self-reported ability to bounce back and recover from stress in the current sample was comparable to previous observations.

Several possible limitations of the project have to be considered. First, as with all longitudinal projects, there is always some amount of drop-out over time, especially for studies running over several years such as the present one. However, in the presented project, the drop-out rate is rather low with $15.3 \%$ from the first baseline to the second baseline assessment and an overall drop-out rate of $21 \%$ over all time points that are currently assessed, undershooting the expected overall drop-out rate of $25 \%$. Second, due to the vast amount of data collected in different modalities, the project places a rather high burden on the participants. As such, sampling biases, such as a self-selection bias, can be expected as well as missing or incomplete data, especially during the interim online stressor monitoring. Not all participants are available over such a long time period or able to come to the baseline measurements during the week. This might result in a rather young sample, consisting of participants who are not working full time yet. Although the present study sample consists of a rather high amount of young and highly educated participants, there is still a good variance in the sample, assuring a generalizability of the findings to the general population. Also, such small sampling biases are rather often in longitudinal studies. Dropouts and missing data are reduced by a repeated reminder scheme for online stressor monitorings via e-mail, regular booster mails to participants, thanking them for their study participation, give-aways with the LORA logo printed on them. Furthermore, participants will be notified of publications of resilience research to become aware of the impact of their contribution to science.

In sum, the LORA study is a unique starting point for a more detailed investigation into resilience mechanisms, in that it investigates these mechanisms, while they actually occur, rather than in a retrospective fashion. As such, the full process, from the occurrence of stressors to a possible recovery from them, can be observed online. In addition, by investigating healthy participants over time, the presented project applies a new and more fine-grained approach to investigate resilience. While the previous studies have mainly focused on resilience by assessing participant's health outcomes (i.e., stress-related psychiatric disorders vs. no disorder), linking them to stressors retrospectively, the presented study uses a forward approach by observing stressors and directly assessing their influence on the human organism. This is done by investigating many distinct domains with respect to their link with resilience and using multiple techniques, such as biological samples, neuropsychological performance, selfrating questionnaires, diagnostic interviews, and individual fitness. Therefore, the LORA study will be able to give information on how these different domains interact and influence each other with regard to resilience outcomes. Furthermore, through the application of more objective measures, such as biological samples, the presented project can advance resilience research. In sum, the LORA study uses a promising approach to shed light on the mechanisms applied in the resilience process.

Acknowledgements Open Access funding provided by Projekt DEAL. This work was funded by the German Research Foundation (DFG CRC 1193, subprojects B01, C01, C04, C05, C07, Z03), the Stiftung Rheinland-Pfalz für Innovation (MARP program, No 961-386261/1080), the Ministry of Science of the state of Rhineland-Palatinate (DRZ program), and the European Union's Horizon 2020 research and innovation program (grant agreements No 777084, 667302 and 728018). We would like to thank all the collaborators for their knowledgeable input and expertise throughout all the phases of the project and for their thorough revision of this manuscript. We are grateful to all the participants who took part in the LORA study and the student assistants, laboratory staff, and lab coordinators who supported the LORA study over the years.

\section{Compliance with ethical standards}

Conflict of interest The authors declare that they have no conflict of interest.

Ethical approval The manuscript does not contain clinical studies or patient data. All procedures were approved by the respective Ethical Committees in Mainz (registration number: 837.105.16(10424)) and Frankfurt (registration number: 244/16), complied with the Declaration of Helsinki (latest version) and written informed consent was obtained from all participants.

Open Access This article is licensed under a Creative Commons Attribution 4.0 International License, which permits use, sharing, adaptation, distribution and reproduction in any medium or format, as long as you give appropriate credit to the original author(s) and the source, provide a link to the Creative Commons licence, and indicate if changes were made. The images or other third party material in this article are included in the article's Creative Commons licence, unless indicated otherwise in a credit line to the material. If material is not included in the article's Creative Commons licence and your intended use is not permitted by statutory regulation or exceeds the permitted use, you will need to obtain permission directly from the copyright holder. To view a copy of this licence, visit http://creativecommons.org/licenses/by/4.0/. 


\section{References}

1. Wittchen H-U, Jacobi F, Rehm J, Gustavsson A, Svensson M, Jönsson B et al (2011) The size and burden of mental disorders and other disorders of the brain in Europe 2010. Eur Neuropsychopharmacol J Eur Coll Neuropsychopharmacol 21(9):655-679. https://doi.org/10.1016/j.euroneuro.2011.07.018

2. Kalisch R, Müller MB, Tüscher O (2015) A conceptual framework for the neurobiological study of resilience. Behav Brain Sci. https ://doi.org/10.1017/S0140525X1400082X

3. Bonanno GA, Mancini AD (2011) Toward a lifespan approach to resilience and potential trauma. In: Southwick SM, Litz BT, Charney D, Friedman MJ (eds) Resilience and mental health. Cambridge University Press, pp 120-134

4. Feder A, Charney D, Collins K (2011) Neurobiology of resilience. In: Southwick SM, Litz BT, Charney D, Friedman MJ (eds) Resilience and Mental Health. Cambridge University Press, pp 1-24

5. Sapienza JK, Masten AS (2011) Understanding and promoting resilience in children and youth. Curr Opin Psychiatry 24(4):267273. https://doi.org/10.1097/YCO.0b013e32834776a8

6. Kanner AD, Coyne JC, Schaefer C, Lazarus RS (1981) Comparison of two modes of stress measurement: daily hassles and uplifts versus major life events. J Behav Med 4(1):1-39. https:// doi.org/10.1007/BF00844845

7. Hu T, Zhang D, Wang J (2015) A meta-analysis of the trait resilience and mental health. Personal Individ Differ 76:18-27. https ://doi.org/10.1016/j.paid.2014.11.039

8. Ong AD, Bergeman CS, Bisconti TL, Wallace KA (2006) Psychological resilience, positive emotions, and successful adaptation to stress in later life. J Pers Soc Psychol 91(4):730-749. https://doi. org/10.1037/0022-3514.91.4.730

9. Kalisch R, Baker DG, Basten U, Boks MP, Bonanno GA, Brummelman E et al (2017) The resilience framework as a strategy to combat stress-related disorders. Nat Human Behav 1(11):784790. https://doi.org/10.1038/s41562-017-0200-8

10. Mancini AD, Bonanno GA (2009) Predictors and parameters of resilience to loss: toward an individual differences model. J Pers 77(6):1805-1832. https://doi.org/10.111 1/j.1467-6494.2009.00601.x

11. Kalisch R, Köber G, Binder H, Ahrens KF, Basten U, Chmitorz A et al (2020). A generic solution for the operationalization and measurement of resilience and resilience processes in longitudinal observations: rationale and basic design of the MARP and LORA studies. https://doi.org/10.31234/osf.io/jg238

12. Reivich K, Shatté A (2002) The resilience factor: Seven essential skills for overcoming life's inevitable obstacles. Broadway Books, New York

13. Southwick SM, Charney DS (2012) Resilience: the science of mastering life's greatest challenges. Cambridge University Press, Cambridge. https://doi.org/10.1017/CBO9781139013857

14. Southwick SM, Litz BT, Charney D, Friedman MJ (2011) Resilience and mental health: challenges across the lifespan. Cambridge University Press. https://doi.org/10.1017/CBO9780511 994791

15. Stewart DE, Yuen T (2011) A systematic review of resilience in the physically Ill. Psychosomatics 52(3):199-209. https://doi. org/10.1016/j.psym.2011.01.036

16. Ackenheil M, Stotz G, Dietz-Bauer R (1999) Mini international neuropsychiatric interview. German version 500, DSM-IV. Psychiatrische Universitätsklinik München, München

17. Lecrubier Y, Sheehan D, Weiller E, Amorim P, Bonora I, Harnett Sheehan K et al (1997) The mini international neuropsychiatric interview (MINI). A short diagnostic structured interview: reliability and validity according to the CIDI. Eur Psychiatry 12(5):224-231. https://doi.org/10.1016/S0924-9338(97)83296-8
18. Goldberg DP (1978) Manual of the General Health Questionnaire. Windsor: NFER-Nelson. https://trove.nla.gov.au/version/11878 284. Accessed 19 May 2016

19. Klaiberg A, Schumacher J, Brähler E (2004) General Health Questionnaire 28-statistical testing of a German version with a representative sample of the general population. Z Klin Psychol Psychiatr Psychother 52(1):31-42

20. Löwe B, Spitzer RL, Zipfel S, Herzog W (2002) PHQ-D Gesundheitsfragebogen für Patienten - Manual Komplettversion und Kurzform, autorisierte deutsche Version des 'Prime MD Patient Health Questionnaire (PHQ; 2nd ed.). Pfizer

21. Spitzer RL, Kroenke K, Williams JB (1999) Validation and utility of a self-report version of PRIME-MD: the PHQ primary care study primary care evaluation of mental disorders patient health questionnaire. JAMA J Am Med Assoc 282(18):1737-1744. https ://doi.org/10.1001/jama.282.18.1737

22. Canli T, Qiu M, Omura K, Congdon E, Haas BW, Amin Z, Herrmann MJ, Constable RT, Lesch KP (2006) Neural correlates of epigenesis. Proc Natl Acad Sci USA 103(43):16033-16038. https ://doi.org/10.1073/pnas.0601674103

23. Chmitorz A, Kalisch R, Kubiak T, Tüscher O (2016) Measuring life stress in young adults: preliminary data of an online questionnaire for stressor monitoring (Poster). Presented at the 15. Kongress der Deutschen Gesellschaft für Verhaltensmedizin und Verhaltensmodifikation, Mainz, Germany

24. Chmitorz A, Kurth K, Mey LK, Wenzel M, Lieb K, Tüscher O, Kubiak T, Kalisch R (2019) Assessment of microstressors in adults: questionnaire development and ecological validation of the Mainz Inventory of Microstressors. JMIR Mental Health. https ://doi.org/10.2196/14566

25. Kurth K, Chmitorz A, Mey L, Wenzel M, Kalisch R, Tüscher O, Kubiak T (2017) Reliability of recalled self-report microstressors - a validation study using ecological ambulatory assessment (Poster). In: Presented at the 5th conference of the Society for Ambulatory Assessment, Luxembourg

26. Bernstein DP, Fink L (1998) Childhood trauma questionnaire: a retrospective self-report questionnaire and manual. The Psychological Corporation, San Antonio. https://doi. org/10.1055/s-0030-1247564

27. Wingenfeld K, Spitzer C, Mensebach C, Grabe H, Hill A, Gast U et al (2010) Die deutsche version des childhood trauma questionnaire (CTQ): erste befunde zu den psychometrischen Kennwerten. PPmP Psychother Psychosom Med Psychol 60(11):442-450. https://doi.org/10.1055/s-0030-1247564

28. Cohen $S$ (1986) Contrasting the hassles scale and the perceived stress scale: who's really measuring appraised stress? Am Psychol 41(6):716-718. https://doi.org/10.1037/0003-066X.41.6.716

29. Teicher $\mathrm{MH}$, Parigger A (2015) The 'maltreatment and abuse chronology of exposure'(MACE) scale for the retrospective assessment of abuse and neglect during development. PLOS ONE 10(2):e0117423. https://doi.org/10.1371/journal.pone.0117423

30. Mollica RF, Caspi-Yavin Y, Bollini P, Truong T, Tor S, Lavelle J (1992) The harvard trauma questionnaire: validating a crosscultural instrument for measuring torture, trauma, and posttraumatic stress disorder in Indochinese refugees. J Nerv Ment Dis 180(2):111-116. https://doi.org/10.1097/00005053-19920 2000-00008

31. Chmitorz A, Wenzel M, Stieglitz R-D, Kunzler A, Bagusat C, Helmreich I et al (2018) Population-based validation of a German version of the brief resilience scale. PLoS ONE 13(2):e0192761. https://doi.org/10.1371/journal.pone.0192761

32. Smith BW, Dalen J, Wiggins K, Tooley E, Christopher P, Bernard J (2008) The brief resilience scale: assessing the ability to bounce back. Int J Behav Med 15(3):194-200. https://doi. org/10.1080/10705500802222972 
33. Garnefski N, Kraaij V, Spinhoven P (2001) Negative life events, cognitive emotion regulation and emotional problems. Personal Individ Differ 30(8):1311-1327. https://doi.org/10.1016/S0191 -8869(00)00113-6

34. Loch N, Hiller W, Witthöft M (2011) Der cognitive emotion regulation questionnaire (CERQ): erste teststatistische Überprüfung einer deutschen Adaption. Z Klin Psychol Psychother 40(2):94106. https://doi.org/10.1026/1616-3443/a000079

35. Vriezekolk JE, van Lankveld WGJM, Eijsbouts AMM, van Helmond T, Geenen R, van den Ende CHM (2012) The coping flexibility questionnaire: development and initial validation in patients with chronic rheumatic diseases. Rheumatol Int 32(8):2383-2391. https://doi.org/10.1007/s00296-011-1975-y

36. Carver CS (1997) You want to measure coping but your protocol's too long: consider the brief COPE. Int J Behav Med 4(1):92-100. https://doi.org/10.1207/s15327558ijbm0401_6

37. Knoll N, Rieckmann N, Schwarzer R (2005) Coping as a mediator between personality and stress outcomes: a longitudinal study with cataract surgery patients. Eur J Pers 19(3):229-247. https:// doi.org/10.1002/per.546

38. Dziobek I, Rogers K, Fleck S, Bahnemann M, Heekeren HR, Wolf OT, Convit A (2007) Dissociation of cognitive and emotional empathy in adults with asperger syndrome using the multifaceted empathy test (MET). J Autism Dev Disord 38(3):464-473. https ://doi.org/10.1007/s10803-007-0486-X

39. Kobasa SC, Maddi SR, Kahn S (1982) Hardiness and health: a prospective study. J Pers Soc Psychol 42(1):168-177. https://doi. org/10.1037/0022-3514.42.1.168

40. Keye D, Wilhelm O, Oberauer K (2009) Structure and Correlates of the German version of the brief UPPS impulsive behavior scale. Eur J Psychol Assess 25(3):175-185. https://doi. org/10.1027/1015-5759.25.3.175

41. Whiteside SP, Lynam DR (2001) The five factor model and impulsivity: using a structural model of personality to understand impulsivity. Personal Individ Differ 30(4):669-689. https://doi. org/10.1016/S0191-8869(00)00064-7

42. Kovaleva A, Beierlein C, Kemper C, Rammstedt B (2012) Eine kurzskala zur messung von impulsivität nach dem upps-ansatz: die skala impulsives-verhalten-8 (I-8). Gesis. Retrieved from https ://pub.uni-bielefeld.de/publication/2575680. Accessed 8 May 2014

43. Paulus C (2009) Der Saarbrücker Persönlichkeitsfragebogen SPF (IRI) zur Messung von empathie: psychometrische evaluation der deutschen version des interpersonal reactivity index. https://hdl. handle.net/20.500.11780/3343. Accessed 19 June 2016

44. Rost-Schaude E, Kumpf M, Frey D (2014) Interne-Externe Kontrolle. In: Danner D, Glöckner-Rist A (eds) Zusammenstellung sozialwissenschaftlicher Items und Skalen. Gesis, Mannheim

45. Rotter JB (1966) Generalized expectancies for internal versus external control of reinforcement. Psychol Monogr 80(1):1-28. https://doi.org/10.1037/h0092976

46. Glaesmer H, Hoyer J, Klotsche J, Herzberg PY (2008) Die deutsche version des life-orientation-tests (LOT-R) zum dispositionellen optimismus und pessimismus. Z Gesundheitspsychologie 16(1):26-31. https://doi.org/10.1026/0943-8149.16.1.26

47. Scheier MF, Carver CS, Bridges MW (1994) Distinguishing optimism from neuroticism (and trait anxiety, self-mastery, and self-esteem): a reevaluation of the life orientation test. J Pers Soc Psychol 67(6):1063-1078. https://doi. org/10.1037//0022-3514.67.6.1063

48. Fydrich T, Geyer M, Hessel A, Sommer G, Brähler E (1999) Fragebogen zur Sozialen Unterstützung (F-SozU): normierung an einer repräsentativen Stichprobe. Diagnostica 45(4):212-216. https://doi.org/10.1026//0012-1924.45.4.212

49. Rammstedt B, Kemper C, Klein MC, Beierlein C, Kovaleva A (2013) Eine kurze skala zur messung der fünf dimensionen der persönlichkeit: big-five-inventory-10 (BFI-10). Methoden Daten Anal (mda) 7(2):233-249. https://doi.org/10.12758/mda.2013.013

50. Krohne HW, Egloff B, Kohlmann CW, Tausch A (1996) Untersuchungen mit einer deutschen Version der" Positive and negative Affect Schedule" (PANAS). Diagn Gott 42:139-156

51. Watson D, Clark LA, Tellegen A (1988) Development and validation of brief measures of positive and negative affect: the PANAS scales. J Pers Soc Psychol 54(6):1063-1070. https://doi. org/10.1037/0022-3514.54.6.1063

52. Connor KM, Davidson JRT (2003) Development of a new resilience scale: the connor-davidson resilience scale (CD-RISC). Depress Anxiety 18(2):76-82. https://doi.org/10.1002/da.10113

53. Sarubin N, Gutt D, Giegling I, Bühner M, Hilbert S, Krähenmann O, Wolf M, Jobst A, Sabaß L, Rujescu D, Falkai P, Padberg F (2015) Erste Analyse der psychometrischen Eigenschaften und Struktur der deutschsprachigen 10- und 25-Item Version der Connor-Davidson Resilience Scale (CD-RISC). Z Gesundheitspsychologie 23(3):112122. https://doi.org/10.1026/0943-8149/a000142

54. Jerusalem M, Schwarzer R (1999) Allgemeine Selbstwirksamkeitserwartung (SWE). In Skalen zur Erfassung von Lehrer- und Schülermerkmalen. Dokumentation der psychometrischen Verfahren im Rahmen der wissenschaftlichen Begleitung des Modellversuchs Selbstwirksame Schule. Freie Universität Berlin, Berlin.

55. Antonovsky A (1987) Unraveling the mystery of health: how people manage stress and stay well, 1st edn. Jossey-Bass Inc., San Francisco

56. Antonovsky A (1997) Salutogenese. Zur Entmystifizierung der Gesundheit. DGVT, Berlin

57. Kemper CJ, Beierlein C, Bensch D, Kovaleva A, Rammstedt B (2012) Eine Kurzskala zur Erfassung des Gamma-Faktors sozial erwünschten Antwortverhaltens: Die Kurzskala Soziale Erwünschtheit-Gamma (KSE-G) [GESIS Working papers]. Retrieved from GESIS website: https://pub.uni-bielefeld.de/publicatio n/2575646. Accessed 19 May 2016

58. Schwenkmezger P, Hodapp V, Spielberger CD (1992) Das StateTrait-Ärgerausdrucks-Inventar (STAXI)—Handbuch, 1st edn. Huber, Göttingen

59. Bech $\mathrm{P}$ (2004) Measuring the dimensions of psychological general well-being by the WHO-5. QoL Newsletter (32). Retrieved from https://www.who-5.org. Accessed 19 May 2016

60. Brähler E, Mühlan H, Albani C, Schmidt S (2007) Teststatistische Prüfung und Normierung der deutschen Versionen des EUROHIS-QOL Lebensqualität-Index und des WHO-5 Wohlbefindens-Index. Diagnostica 53(2):83-96. https://doi. org/10.1026/0012-1924.53.2.83

61. Arbeitskreis Deutscher Markt- und Sozialforschungsinstitute e. V., Arbeitsgemeinschaft Sozialwissenschaftlicher Institute e. V., \& Statistisches Bundesamt (1999) Demographische Standards-Methoden-Verfahren- Entwicklung

62. Nesterko Y, Glaesmer H (2019) Warum fragen wir nicht direkt nach? Psychol Rundsch 70(2):101-108. https://doi. org/10.1026/0033-3042/a000399

63. Saunders JB, Aasland OG, Babor TF, de la Fuente JR, Grant M (1993) Development of the alcohol use disorders identification test (AUDIT): WHO collaborative project on early detection of persons with harmful alcohol consumption-II. Addiction 88(6):791804. https://doi.org/10.1111/j.1360-0443.1993.tb02093x

64. Heatherton TF, Kozlowski LT, Frecker RC, Fagerström KO (1991) The Fagerström test for nicotine dependence: a revision of the Fagerström tolerance questionnaire. Br J Addict 86(9):1119-1127. https://doi.org/10.1111/j.1360-0443.1991.tb01879.x

65. Craig CL, Marshall AL, Sjöström M, Bauman AE, Booth ML, Ainsworth BE et al (2003) International physical activity questionnaire: 12-country reliability and validity. Med Sci Sports Exerc 35(8):1381-1395. https://doi.org/10.1249/01.MSS.00000 78924.61453.FB 
66. Helmerhorst HJ, Brage S, Warren J, Besson H, Ekelund U (2012) A systematic review of reliability and objective criterion-related validity of physical activity questionnaires. Int J Behav Nutr Phys Act 9(1):103. https://doi.org/10.1186/1479-5868-9-103

67. Ortega FB, Ruiz JR, España-Romero V, Vicente-Rodriguez G, Martínez-Gómez D, Manios Y et al (2011) The international fitness scale (IFIS): usefulness of self-reported fitness in youth. Int J Epidemiol 40(3):701-711. https://doi.org/10.1093/ije/dyr039

68. Armbruster DJN, Ueltzhöffer K, Basten U, Fiebach CJ (2012) Prefrontal cortical mechanisms underlying individual differences in cognitive flexibility and stability. J Cogn Neurosci 24(12):23852399. https://doi.org/10.1162/jocn_a_00286

69. Stahl C, Voss A, Schmitz F, Nuszbaum M, Tüscher O, Lieb K, Klauer KC (2014) Behavioral components of impulsivity. J Exp Psychol Gen 143(2):850-886. https://doi.org/10.1037/a0033981

70. MacLeod C, Mathews A, Tata P (1986) Attentional bias in emotional disorders. J Abnorm Psychol 95:15-20

71. Schick A, Wessa M, Vollmayr B, Kuehner C, Kanske P (2013) Indirect assessment of an interpretation bias in humans: neurophysiological and behavioral correlates. Front Hum Neurosci 7:27. https://doi.org/10.3389/fnhum.2013.00272

72. Schönfelder S, Kanske P, Heissler J, Wessa M (2014) Time course of emotion-related responding during distraction and reappraisal. Soc Cogn Affect Neurosci 9(9):1310-1319. https://doi. org/10.1093/scan/nst116

73. Kanske P, Heissler J, Schönfelder S, Bongers A, Wessa M (2011) How to regulate emotion? Neural networks for reappraisal and distraction. Cereb Cortex 21(6):1379-1388. https://doi.org/10.1093/cercor/bhq216

74. Stalder T, Kirschbaum C (2012) Analysis of cortisol in hair-State of the art and future directions. Brain Behav Immun 26(7):10191029. https://doi.org/10.1016/j.bbi.2012.02.002

75. Wenning R (2000) Potential problems with the interpretation of hair analysis results. Forensic Sci Int 107:5-12. https://doi. org/10.1016/s0379-0738(99)00146-2

76. World Health Organization (2008) WHO steps surveillance, section 3: guide to physical measurements (Step 2). Retrieved from https://apps. who.int/iris/handle/10665/43376. Accessed 19 May 2016

77. Grimm J (2009) State-trait-anxiety inventory nach Spielberger. Deutsche Lang- und Kurzversion. Methodenforum der Universität Wien: MF-Working Paper 2009/02, Wien

78. Spielberger CD (1989) State-Trait Anxiety Inventory: Bibliography, 2nd edn. Consulting Psychologists Press, Palo Alto

79. Staufenbiel SM, Penninx BW, Spijker AT, Elzinga BM, van Rossum EF (2013) Hair cortisol, stress exposure, and mental health in humans: a systematic review. Psychoneuroendocrinology 38(8):1220-1235. https://doi.org/10.1016/j.psyneuen.2012.11.015

80. Zannas AS, West AE (2014) Epigenetics and the regulation of stress vulnerability and resilience. Neuroscience 264:157-170. https://doi.org/10.1016/j.neuroscience.2013.12.003

81. Elbau IG, Cruceanu C, Binder EB (2019) Genetics of resiliencegene-by-environment interaction studies as a tool to dissect mechanisms of resilience. Biol Psychiatry. https://doi.org/10.1016/j. biopsych.2019.04.025

82. Hegberg NJ, Tone EB (2015) Physical activity and stress resilience: considering those at-risk for developing mental health problems. Ment Health Phys Act 8:1-7. https://doi.org/10.1016/j. mhpa.2014.10.001
83. Tsatsoulis A, Fountoulakis S (2006) The protective role of exercise on stress system dysregulation and comorbidities. Ann N Y Acad Sci 1083(1):196-213. https://doi.org/10.1196/annal s. 1367.020

84. Mujica-Parodi LR, Renelique R, Taylor MK (2009) Higher body fat percentage is associated with increased cortisol reactivity and impaired cognitive resilience in response to acute emotional stress. Int J Obes 33(1):157. https://doi.org/10.1038/ijo.2008.218

85. Knowles SR, Nelson EA, Palombo EA (2008) Investigating the role of perceived stress on bacterial flora activity and salivary cortisol secretion: a possible mechanism underlying susceptibility to illness. Biol Psychol 77:132-137. https://doi.org/10.1016/j. biopsycho.2007.09.010

86. Enzenbach C, Wicklein B, Wirkner K, Loeffler M (2019) Evaluating selection bias in a population-based cohort study with a low baseline participation: the LIFE-adult-study. BMC Med Res Methodol 19(135):1-14. https://doi.org/10.1186/s12874-019-0779-8

87. Henrich J, Heine SJ, Norenzayan A (2010) Most people are not WEIRD. Nature 466(7302):29-29. https://doi.org/10.1038/466029a

88. Cavallo P, Carpinelli L, Savarese G (2016) Perceived stress and bruxism in university students. BMC Res Notes 9(514):2-6. https ://doi.org/10.1186/s13104-016-2311-0

89. Osman M-A, Neoh H-M, Ab Mutalib N-S, Chin S-F, Jamal R (2018) 16S rRNA gene sequencing for deciphering the colorectal cancer gut microbiome: current protocols and workflows. Front Microbiol 9:767. https://doi.org/10.3389/fmicb.2018.00767

90. Kunzler AM, Chmitorz A, Bagusat C, Kaluza AJ, Hoffmann I, Schäfer M et al (2018) Construct validity and population-based norms of the German brief resilience scale (BRS). Eur J Health Psychol. https://doi.org/10.1027/2512-8442/a000016

91. Goldberg DP, Gater R, Sartorius N, Ustun TB, Piccinelli M, Gureje O, Rutter C (1997) The validity of two versions of the GHQ in the WHO study of mental illness in general health care. Psychol Med 27(1):191-197. https://doi.org/10.1017/S003329179 6004242

92. Marfell-Jones M, Olds T, Stewart A Carter L (2006) International standards for anthropometric assessment. The international society for the advancement of Kim anthropometric (ISAK), Potchefsroom, South Africa

93. Sykes K, Roberts A (2004) The Chester step test-a simple yet effective tool for the prediction of aerobic capacity. Physiotherapy 90(4):183-188. https://doi.org/10.1016/j.physio.2004.03.008

94. España-Romero V, Ortega FB, Vicente-Rodríguez G, Artero EG, Rey JP, Ruiz JR (2010) Elbow position affects handgrip strength in adolescents: validity and reliability of Jamar, DynEx, and TKK dynamometers. J Strength Cond Res 24(1):272-277. https://doi. org/10.1519/JSC.0b013e3181b296a5

95. Castro-Piñero J, Ortega FB, Artero EG, Girela-Rejón MJ, Mora J, Sjöström M, Ruiz JR (2010) Assessing muscular strength in youth: usefulness of standing long jump as a general index of muscular fitness. J Strength Cond Res 24:1810-1817. https://doi. org/10.1519/JSC.0b013e3181ddb03d 


\section{Affiliations}

\section{A. Chmitorz ${ }^{1,2} \cdot$ R. J. Neumann ${ }^{3} \cdot$ B. Kollmann ${ }^{1,4}$ - $\cdot$ K. F. Ahrens ${ }^{3} \cdot$ S. Öhlschläger ${ }^{3}$ N N. Goldbach ${ }^{3} \cdot$ D. Weichert ${ }^{1}$.}

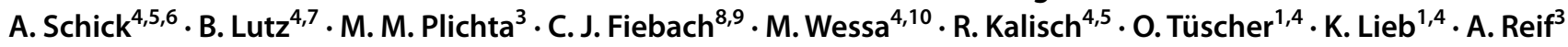

1 Department of Psychiatry and Psychotherapy, University Medical Center Mainz, Mainz, Germany

2 Faculty of Social Work, Health Care and Nursing Science, Esslingen University of Applied Sciences, Esslingen am Neckar, Germany

3 Department of Psychiatry, Psychosomatic Medicine and Psychotherapy, University Hospital Frankfurt, Frankfurt, Germany

4 Leibniz Institute for Resilience Research (LIR), Wallstraße 7, Mainz 55122, Deutschland

5 Neuroimaging Center (NIC), Focus Program Translational Neuroscience (FTN), University Medical Center Mainz, Mainz, Germany
6 Department of Public Mental Health, Central Institute of Mental Health, Medical Faculty Mannheim, Heidelberg University, Mannheim, Germany

7 Department of Physiological Chemistry, University Medical Center Mainz, Mainz, Germany

8 Department of Psychology, Goethe University Frankfurt, Frankfurt am Main, Germany

9 Brain Imaging Center, Goethe University, Frankfurt, Germany

10 Department of Clinical Psychology and Neuropsychology, Institute for Psychology, Johannes Gutenberg University Mainz, Mainz, Germany 